\title{
Role of Spirometry in the Diagnosis of COPD
}

\author{
Lalithasurulichamy $^{1}$, Anandhalakshmi Swaminathan ${ }^{2 *}$, Saravanan Ayyavoo ${ }^{2}$ \\ ${ }^{I}$ Department of Physiology, Sri Ramachandra Medical College and Research \& Research \\ Institute, Porur, Chennai, Tamil Nadu, India. \\ ${ }^{2}$ Department of Physiology, SRM Medical College Hospital \& Research Centre, \\ Potheri, Kattankulathur, Chennai, Tamil Nadu, India.
}

\begin{abstract}
:
Introduction: Chronic obstructive pulmonary disease (COPD) is an airflow obstruction disease that is not completely reversible. It includes chronic obstructive bronchiolitis with fibrosis and obstruction of small airways. Spirometry is an important tool used for assessing conditions such as asthma, pulmonary fibrosis, cystic fibrosis and COPD.

Aim: To assess the pulmonary functions in COPD subjects and in normal individuals

Methods and materials: This prospective study was carried out in 30 COPD patients attending the department of Pulmonology, SRM medical college hospital and research centre. Thirty (30) age and sex matched healthy individuals were taken for control group. This study was performed between July 2012 and December 2012.

Results: The statistical analysis was done using SPSS17.0 software. The data were expressed as mean \pm standard deviation. The pulmonary function test parameters between the COPD and control, FVC $\quad(62.14 \pm 8.86$

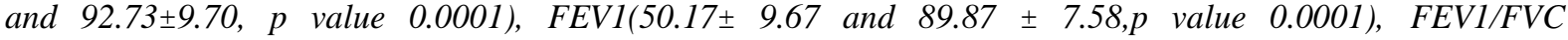
ratio(68.41 \pm 16.99 and $96.93 \pm 6.91, p$ value 0.0001$)$ shows highly significant ' $p$ 'S values.

Conclusion: The gold standard for diagnosing COPD is Spirometry. Pulmonary function testing can also be useful in evaluating the severity of disease and in treatment of the disease once diagnosed.
\end{abstract}

Keywords: $C O P D, P F T$

\section{Introduction}

Chronic obstructive pulmonary disease (COPD) is an airflow obstruction disease that is not completely reversible. It includes chronic obstructive bronchiolitis with fibrosis and obstruction of small airways, and emphysema with enlargement of airspaces and destruction of lung parenchyma, loss of lung elasticity and closure of small airways [1].It is progressive, associated with severe $\&$ declining lung functions. Risk factors of COPD are both genetic and environmental and the most common etiological agent is cigarette smoking. The estimated prevalence of COPD (Global Initiative for Chronic Obstructive Lung Disease (GOLD) Stage II and higher) is $5.3 \%-14.9 \%$ in the population [8].

The diagnosis and classification of disease severity is based on pulmonary function; a forced expiratory volume in 1 second (FEV1.0) relative to forced vital capacity (FVC) of less than $70 \%$ post bronchodilator is used to diagnose COPD.

In 1990, COPD was positioned sixth as a cause of death by the Global Burden of Disease Study and predicted to be the third leading cause of death by 2020. It is also estimated to be the fourth leading cause of death in 2030 [2]. In Indian patients 30 years and above, it is shown to have a prevalence of around 1.49crores. The prevalence rate in males range from $2.12 \%$ to $9.4 \%$ in studies conducted in north India to $1.4 \%$ to $4.08 \%$ in studies conducted in south India[3].

Spirometry is the most common of the pulmonary function tests, measuring lung function, specifically the measurement of the amount (volume) or speed(flow) of air that can be inhaled and exhaled. Spirometry is an important tool used for assessing conditions such as asthma, pulmonary fibrosis, cystic fibrosis, and COPD. Results are visualised in time-volume and flow-volume curve and the most relevant results for COPD are the forced expiratory volume in one second (FEV1) and the forced vital capacity (FVC).

\section{Aim \& Objective}

To assess the Pulmonary function test in COPD subjects and in normal individuals

\section{Materials \& Methods}

This prospective study was carried out in 30 COPD patients attending the Department of Pulmonology, SRM Medical College hospital and Research Centre. Thirty (30) age and sex matched healthy individuals were taken for control group. This study was performed between July 2012 and December 2012. 
The study was approved by the institutional ethical committee and a written consent from the subjects was obtained for carrying out the study after explaining to them the procedure. A detailed history from the subjects, weight, height etc were obtained and PFT parameters such as FVC(L) Forced Vital Capacity, FEV1(L), Forced Expiratory Volume in one second FEV1/FVC were estimated using Easy One Pro computerized spirometry Instrument.30 normal individuals and 30 COPD patients in the age group 25-50 years were included in the study. Subjects not fitting the age range of 25-50 years and having any systemic illness were excluded.

\section{Statistical Analysis}

The statistical analysis was done using SPSS17.0 software. The data were expressed as mean \pm standard deviation. Student t- test was applied to compare the PFT parameters between COPD (GROUP I) and control (GROUP II)."p' value of $<0.05$ was considered to be significant.

\section{Results}

The pulmonary function test parameters between the COPD and control, the mean and standard

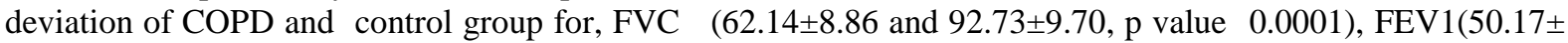
9.67 and $89.87 \pm 7.58, p$ value 0.0001$)$, FEV1/FVC Ratio(68.41 \pm 16.99 and $96.93 \pm 6.91, p$ value 0.0001$)$ Shows highly significant ' $p$ ' values

Table 1: Comparison of FVC,FEV1,FEV1/FVC between COPD and Control Group

\begin{tabular}{|l|l|l|l|}
\hline Parameter & $\begin{array}{l}\text { Group I } \\
\text { COPD }(n=30) \\
\text { Mean } \pm \text { SD }\end{array}$ & $\begin{array}{l}\text { Group II IControl (n=30) } \\
\text { Mean } \pm \text { SD }\end{array}$ & p Value \\
\hline FVC (L) & $62.14 \pm 8.86$ & $92.73 \pm 9.70$ & $0.0001 \mathrm{~S}$ \\
\hline FEV1 (L) & $50.17 \pm 9.67$ & $89.87 \pm 7.58$ & $0.0001 \mathrm{~S}$ \\
\hline FEV1/FVC & $68.41 \pm 16.99$ & $96.93 \pm 6.91$ & $0.0001 \mathrm{~S}$ \\
\hline
\end{tabular}

$\mathrm{S}-$ Significant

Chart 1: Comparison of FVC, FEV1 and FEV1/ FVC

\section{Discussion}

\section{Comparison of FVC, FEV1 and FEV1/FVC}

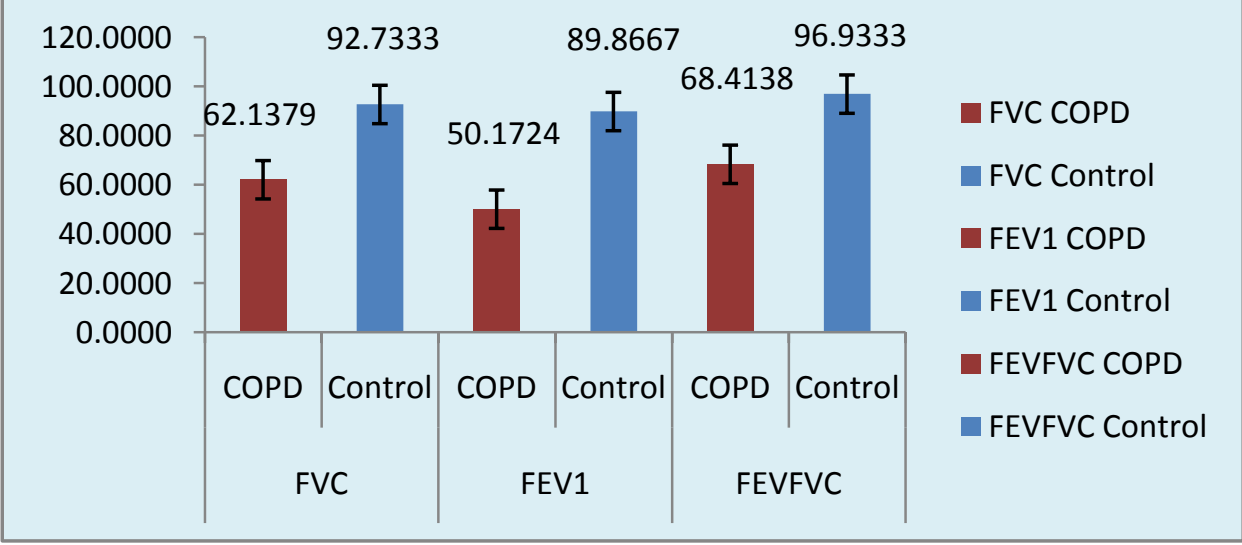

Spirometry was done for all the 60 subjects to assess the lung function. It shows decreased forced expiratory volume in 1 second (FEV1) with concomitant reduction in (FEV1)/ forced vital capacity, (FEV1/ FVC) ratio with poor/absent bronchodilator reversibility and reduced FVC for the group I (COPD) subjects.

In our study we had $26.66 \%$ subjects with mild COPD,56.66\% subjects with moderate COPD, $16.66 \%$ were severe COPD cases and no very severe COPD category cases were observed in study (classified based on 
Canadian Thoracic Society COPD). Mechanisms that have been proposed to influence sympathetic activity in patients with COPD include systemic inflammation, hypoxia, oxidative stress, physical inactivity, and large intrathoracic pressure changes.

According to Heindl,Set al., and Hardy et al., patients with COPD often develop hypoxia which may be present intermittently (eg. during exacerbations or related to desaturations during sleep) or sustained in more severe cases[4]. Buch P Set al., suggested that the etiology of arrhythmia in patients with COPD is multifactorial and includes a number of risk factors such as hypoxemia, acidosis, and reduced $\mathrm{FEV}_{1}[5]$.

According to Anthonisen NR et.al, mortality increases with decreasing FEV1[6]. Few studies suggest that FEV 1 alone cannot diagnose COPD. Other combinations of criteria, which include the FEV1 are being studied such as the BODE index [7].

Shah sanket et.al., found that subjects with higher pack year of smoking and lower BMI had more deficiency to Vitamin D[8]. O'Donnell has suggest that bronchodilator therapy might benefit patients with chronic airflow limitation, and many authors have demonstrated that breathlessness can be relieved with various bronchodilators in the presence of only small improvements in FEV1[9].

Tweeddale and colleagues found that the increase in FEV1 and FVC that excluding natural variability with $95 \%$ confidence in patients with obstructive ventilatory defects was $160 \mathrm{ml}$ and $330 \mathrm{ml}$ respectively[10]. It was not specified whether these values were applicable for both COPD and asthma that study. In the assessment of obstructive lung disease spirometry remains an analytical tool to differentiate between COPD and asthma.

\section{Conclusion}

The gold standard for diagnosing COPD is spirometry. Other pulmonary functions such as lung volumes can give you insight into physiological consequences of COPD such as hyperinflation. Pulmonary function testing can also be useful in evaluating the severity of disease and in treatment of the disease once diagnosed.

\section{References}

[1]. Rabe KF, Hurd S, Anzueto A, Barnes PJ, Buist SA, Calverley P, et al. Global strategy for the diagnosis, management, and prevention of chronic obstructive pulmonary disease: GOLD executive summary. Am J Respir Crit Care Med. 2007 Sep 15; 176(6):532-555.

[2]. Buist AS, Vollmer WM, McBurnie MA. Worldwide burden of COPD in high- and low-income countries. Part I. The burden of obstructive lung disease (BOLD) initiative. Int J Tuberc Lung Dis. 2008;12(7):703-08.

[3]. S.K.Jindal, A.N.Aggarwal,D.Gupta, A review of population studies from India to estimate national burden of chronic obstruction pulmonary disease and its association with smoking. The Indian journal of chest diseases and allied sciences. 43, 139-147,2001.

[4]. Heindl, S, Lehnert, M, Criée, CP. Marked sympathetic activation in patients with chronic respiratory failure.Am J RespirCrit Care Med 164:597-601, 2001

[5]. Buch P, Friberg J, Scharling H, Lange P, Prescott E. Reduced lung function and the risk of atrial fibrillation in the Copenhagen City Heart Study. EurRespir J 21:1012-1016, 2003.

[6]. Anthonisen NR, Wright EC, Hodgkin JE. Prognosis in chronic obstructive pulmonary disease. Am Rev Respir Dis. 1986 Jan; 133(1):14-20.

[7]. Cote CG, Pinto-Plata VM, Marin JM, Nekach H, Dordelly LJ, Celli BR. The modified BODE index: validation with mortality in COPD. Eur Respir J. 2008 Nov; 32(5):1269-1274.

[8]. Shah sanket1, Jagadesh madireddi2, Weena stanley3, Pradeepsura4, Mukhyaprana prabhu5, Relation between Vitamin D Deficiency and Severity of Chronic Obstructive Pulmonary Disease-A Case Control Study, Journal of Clinical and Diagnostic Research. 2016 Jan, Vol-10(1): OC16-OC19

[9]. Denis E. O’Donnell, MD, FCCP Assessment of Bronchodilator Efficacy in Symptomatic COPD .Is Spirometry Useful? chest / 117/2/ february, 2000 supplement pages 42- 47.

[10]. Tweeddale PM, Alexander F, McHardy GJR. 1987. Short term variability in FEV1 and bronchodilator responsiveness in patients with obstructive ventilatory defects. Thorax, 42:487-90. 